I Sección:

Miradas a la trayectoria centroamericana en los casi dos siglos de independencia

\title{
Costa Rica contemporánea, una sociedad dividida: empobrecimiento y movimientos sociales, una introducción
}

\author{
Javier Agüero García \\ Universidad de Costa Rica, Costa Rica \\ jav aguero@hotmail.com \\ https://orcid.org/0000-0002-6869-1157
}

Recibido: 19 de setiembre de 2019

Aceptado: 16 de octubre de 2019

Resumen: Este ensayo constituye una interpretación introductoria acerca del empobrecimiento y los movimientos sociales en Costa Rica, a partir de los años ochenta. Para la realización del análisis, se estudian los fenómenos de pauperización de los sectores medios, la proliferación de los nuevos pobres y las problemáticas vinculadas con la exclusión. En un segundo momento se abordan los movimientos sociales, a partir de las problemáticas que marcaron el período: la huelga de maestros en 1995, las protestas contra el Combo del ICE en 2000 y las manifestaciones masivas contra el TLC en 2006-2007. Bajo la perspectiva de la historia reciente, se consultan fuentes basadas en el Programa del Estado de la Nación, prensa escrita y textos ya publicados. Al final, se concluye en el reconocimiento de la compleja realidad social costarricense, caracterizada por el ensanchamiento de las brechas entre ricos y pobres; $y$ el aumento del descontento expresado en las protestas callejeras.

Palabras clave: Historia reciente; Costa Rica; crisis; empobrecimiento; movimientos sociales

\section{Contemporany Costa Rica, a divided society. Impoverishment and social movements, An introduction}

Abstract:This essay constitutes an introductory interpretation about impoverishment and social movements in Costa Rica, beginning in the 1980s. To carry out the analysis, the phenomena of pauperization of the middle sectors, the

\section{(c) (i) (2) (2)}

La Revista Estudios es editada por la Universidad de Costa Rica y se distribuye bajo una Licencia Creative Commons Atribución-NoComercial-CompartirIgual 3.0 Costa Rica. Para más información envíe un mensaje a 
proliferation of the new poor and the problems associated with exclusion are studied. In a second moment, the social movements are approached, based on the problems that marked the period: the teachers' strike in 1995, the protests against the Combo del ICE in 2000 and the mass demonstrations against the TLC in 20062007. From the perspective of recent history, sources based on the Programa del Estado de la Nación, written press and texts already published are consulted. In the end, it concludes in the recognition of the complex Costa Rican social reality, characterized by the widening of the gaps between rich and poor; and the increase in discontent expressed in street protests.

Keyword: Recent history; Costa Rica; crisis; impoverishment; social movements

\section{Introducción}

Históricamente, a partir de la puesta en ejecución de los programas de ajuste estructural durante la segunda parte de los años ochenta, se empezó a vislumbrar un modelo social caracterizado por un nuevo estilo de desarrollo muy bien retratado por Antonio Hidalgo-Capitán (2003), una lúcida interpretación del giro experimentado por Costa Rica en la esfera productiva, resultado de la aprobación y puesta en marcha de los programas de ajuste estructural (PAE), como una respuesta para hacerle frente a la crisis desatada, a partir de 1981, cuando las autoridades gubernamentales, de la administración de Rodrigo Carazo (19781982), decidieron no cumplir con lo demandado por los organismos financieros internacionales (Rovira, 1989, p. 56).

Desde el inicio de la crisis, hasta nuestros días, han transcurrido cuarenta años y los embates de esa distorsión económica aún resuenan en diferentes ámbitos de la vida de los costarricenses, máxime si se le adiciona que en estas décadas, han sucedido fenómenos que han complejizado el acontecer social del país. Es ese acontecer, el objeto de estudio del presente ensayo, consiste en analizar, de manera preliminar; por un lado, el rostro más visible en quienes quedan por fuera de los beneficios de una economía con un crecimiento medio; inserta en un proceso de pauperización de amplios sectores sociales, la emergencia de los nuevos pobres y la exclusión. Por otro lado, se estudian los movimientos sociales, caracterizados por constituir momentos clave en el 
horizonte de la efervescencia social: en 1995, con la lucha magisterial en contra de la modificación a la ley de pensiones; en 2000, con oposición al proyecto de una ley de modernización del sector de telecomunicaciones; y en 2006-2007, con la protesta generalizada adversaria a la firma del Tratado de Libre Comercio con Estados Unidos.

Al mismo tiempo, es menester aclarar que este estudio por constituir un ensayo de historia reciente, se han consultado los valiosos aportes preparados y socializados por el Programa del Estado de la Nación (PEN), así como noticias publicadas en diferentes medios impresos o digitales, además de fuentes secundarias.

Se advierte que por la naturaleza introductoria de este documento, se obvian las discusiones teóricas tan interesantes como necesarias en las ciencias sociales; pero que por razones de espacio resultan difíciles de tratar. Del mismo modo, tampoco se adentra a desentrañar las relaciones políticas de un período tan rico en cuanto a la configuración de fuerzas, dentro de la dinámica móvil de los partidos políticos a lo largo del período.

\section{Costa Rica a partir de 1980}

En 1995, el Programa de Estado de la Nación (PEN) publicó su primer informe bajo el lema: "Conocer la Costa Rica que tenemos. Pensar la Costa Rica que deseamos". EI PEN es un producto de un esfuerzo del PNUD, la Defensoría de los Habitantes y las universidades públicas. Dicho informe ponía de manifiesto la información de cómo era Costa Rica seis años antes de culminar el siglo XX; por otro lado, en una coyuntura más amplia, reconocía que Costa Rica había experimentado uno de los crecimientos económicos más altos de Latinoamérica; además su modelo de estabilidad constituyó una referencia obligada para el área centroamericana.

\section{(C) $(0 \otimes)$}

La Revista Estudios es editada por la Universidad de Costa Rica y se distribuye bajo una Licencia Creative Commons Atribución-NoComercial-CompartirIgual 3.0 Costa Rica. Para más información envíe un mensaje a 
El Índice de Desarrollo Humano (IDH) que mide el disfrute de una vida prolongada, ubicó a Costa Rica en el puesto 28, más que aceptable dentro de la posición de los países. Merced a las mejoras necesarias para tener una vida digna, la cobertura de educación, la esperanza de vida al nacer. Algunas cifras mostradas a continuación, indican el cambio ocurrido entre 1940 y 1990, al calor del desarrollo de un Estado de Bienestar.

-La población pasó de 656.000 a 3.029.000.

-La esperanza de vida al nacer pasó de 46,9 a 75,6 años.

-La mortalidad infantil pasó de 123 a 15 por cada 1.000 habitantes.

-El analfabetismo en mayores de 12 años pasó de $27 \%$ al $7 \%$.

La evolución del país en esos años fue impactante. Solo la esperanza de vida al nacer aumentó en casi treinta años y aunque el nivel de deuda con el exterior también aumentó; resulta interesante que los indicadores de pobreza retrocedieron dado que en 1960 cinco de cada diez familias eran pobres. No obstante, para la década de los ochenta el sistema de bienestar social diseñado cincuenta años antes empezó a hacer crisis en el contexto de una crisis mayor del capitalismo occidental, en parte por las deficiencias intrínsecas del estilo de desarrollo. Las medidas adoptadas para paliar la crisis; significaron un importante sacrificio para la población del país. El nuevo paradigma de desarrollo, basado en una nueva lógica de acumulación, resultante de la implementación de las nuevas medidas, se cimentó en el apoyo a la apertura comercial en momentos adversos que impedían dar el salto hacia el desarrollo. Entre ese escenario desfavorable para 1990, se señalan los aspectos siguientes.

-El modelo agroexportador aún mantenía su presencia en el PIB como generador de divisas; no obstante su vitalidad dependía de los incentivos y subsidios para apuntalar la producción.

-El desarrollo del capital educativo había ha tenido limitaciones de estructura, dado que la educación técnica se expandió lentamente. Esto sin tomar en cuenta que la deserción escolar y la baja calidad de la educación formal se

La Revista Estudios es editada por la Universidad de Costa Rica y se distribuye bajo una Licencia Creative Commons Atribución-NoComercial-CompartirIgual 3.0 Costa Rica. Para más información envíe un mensaje a 
concentra en el $80 \%$ de las familias pobres, constituidas por hogares cuyo entorno educativo era inferior al promedio nacional.

La pobreza tenía su antecedente inmediato en un aumento vertiginoso registrado en 1982 cuando llegó a un 55\%; concentrándose sobre todo en el mundo rural. En 1995, el 10\% más rico de las áreas urbanas acaparaba el 42\% del ingreso. La desigualdad social se acrecentaba más que todo en las zonas periféricas de las ciudades.

Los gastos en salud y educación, que habían sido los grandes rubros de asignación de los presupuestos, disminuyeron considerablemente en beneficio del fortalecimiento de sectores como vivienda y asistencia social. El Estado empezó a brindar ayuda focalizada a los sectores más desfavorecidos de la implementación del ajuste estructural.

En 2013, a casi veinte años del primer diagnóstico reseñado con antelación, según el Décimonoveno Informe del Estado de la Nación, era imperioso despejar algunos mitos para así darle un rumbo a Costa Rica que se quería construir. Algunas de estas visiones falsas de la realidad del país son:

-La pobreza siempre afecta a la misma población y solo puede ser subsanada en el momento en que se mejoran las políticas sociales. Frente a esto debe considerarse que hay nuevos pobres y además para combatir la pobreza es necesario crear empleos estables.

-La creciente desigualdad de ingresos es un resultado de la tendencia mundial. Aunque exista un comportamiento general en torno a la desigualdad de ingresos en América Latina la situación tiende a ser diferente en 2011, dieciocho países lograron revertir esta característica al menos parcialmente; mientras que en Costa Rica la situación es muy distinta: entre 2001 y 2011 fue el único país de la región donde aumentó el coeficiente de Gini, indicador que mide el nivel de desigualdad social.

-La mayor parte de trabajadores cuenta con empleos formales en los que se respetan todas las garantías sociales. Solamente un $38,8 \%$ de los trabajadores

\section{() $(\triangle \otimes 0$}

La Revista Estudios es editada por la Universidad de Costa Rica y se distribuye bajo una Licencia Creative Commons Atribución-NoComercial-CompartirIgual 3.0 Costa Rica. Para más información envíe un mensaje a revistaestudios.eeg@ucr.ac.cr. 
asalariados disfruta de todos los derechos laborales contemplados en la ley. En los casos de las personas que reciben menos del salario mínimo se evidencia, con mayor claridad, el atropello de sus derechos.

En la misma línea, el Quinto Estado de la Educación Costarricense hace hincapié en poner sobre la mesa la falsedad de considerar a Costa Rica con una población altamente educada y calificada. Aunque posea una tasa de alfabetización es de 97,6\%, la tasa neta de escolarización del ciclo diversificado, llega apenas al 46,9\%, pese a que dicho ciclo se estableció como obligatorio. Además, la mayor parte de los estudiantes obtuvieron resultados en un rango de medio a bajo en la prueba Programa para la Evaluación Internacional de Alumnos (PISA) de la Organización para la Cooperación y Desarrollo Económico (OCDE), dicho rendimiento ubica al país en la posición 55 según datos de 2016.

Finalmente, una gran parte de la mano de obra es no calificada. Solo una minoría tiene un perfil de competencias requerida por los sectores económicos más dinámicos. Más de un $60 \%$ de los desocupados no cuentan con la secundaria concluida. (PEN, 2015a, pp. 31-33).

\section{Empobrecimiento}

Pese a que los costarricenses expresen con el coloquial "pura vida" que todo marcha bien, la realidad apunta hacia otra situación: el país se enrumba por el camino caracterizado por la pauperización de amplios sectores de clase media; el ensanchamiento de la brecha entre ricos y pobres; junto con la emergencia del fenómeno de exclusión social. Todo esto, en parte, es un efecto de la contracción del empleo público, las políticas de liberalización económica y las dificultades para ascender socialmente.

Aunque en el imaginario social aún persista el referente de ser igualiticos, cuya evocación es casi idílica al tomar como punto de anclaje la imagen de una antigua Arcadia cuando todo era mejor, en realidad, la desigualdad social es el 
fenómeno predominante en las últimas décadas. Costa Rica se ha escindido en más de dos, o más aún, casi que existen cinco costarricas; cada una definida de acuerdo con los quintiles de ingreso, sean estos superiores o inferiores. En el criterio de Mylena Vega (1996), los sectores medios han perdido su nivel de ingresos reales; aspecto muy significativo, máxime si se vincula con la manera en que los costarricenses se imaginan a sí mismos como un país predominantemente de clases medias, pese a que ha prevalecido históricamente una desigual estructura de clases; la prueba es que en 1987, la clase baja representaba un $72,1 \%$. Además del pronunciado deterioro en los ingresos de la clase media; aspecto responsable de que este grupo social pierda la ventaja, aunada a una contracción del empleo público motivada por el cambio de orientación del Estado (Vega, 1996, pp. 136-138).

Al respecto, según Sojo (2010) y Mora y Pérez (2009) se pueden establecer las relaciones siguientes basadas en el nivel de ingreso de los grupos sociales entre 1984 y 2004.

-El valor del coeficiente de Gini pasó de 0,358 a 0,475. Para 1988 el 20\% más rico recibía un ingreso personal de $11 \%$ superior al del $20 \%$ más pobre; en tanto que para 2004, la diferencia pasó de 11 a 20 veces. Durante esos mismos años la quinta parte de las familias más ricas pasó a acumular $43 \%$ del total del ingreso, mientras que para el último año (2004) captaba el 54\%. Por otro lado, el grupo más pobre de las familias que para 1984 captaba el 6\%, redujo su participación y para el 2004, captaba solo el $4 \%$.

-El $20 \%$ de los hogares más pobres concentra el $24 \%$ del total de la población. El $20 \%$ más pobre concentra más del doble de los niños y de los adolescentes con respecto al $20 \%$ más rico. Solo el $13 \%$ de los jóvenes de 15 años, ubicados en el quintil más pobre, completó el noveno de secundaria; contrario sensu, en el quitil más alto aumenta a $90 \%$.

-El ingreso per-cápita del $20 \%$ más pobre de las familias debe ser multiplicado 1.025 veces para adquirir un automóvil de 33.000 dólares. Ese mismo 
ingreso debe ser multiplicado 3.106 veces para comprar una vivienda de 45 millones de colones.

Lo anterior se atribuye en gran medida al aumento de la riqueza sin una adecuada redistribución. Sojo (2010) sostiene que nunca antes había habido un nivel de desigualdad tan acentuado, producto a su vez de la articulación de una nueva arquitectura económica que ha amainado el integracionismo social (Sojo, 2010, pp.10 y 84-85). De acuerdo con lo expuesto en el Décimonoveno Informe del Estado de la Nación, Costa Rica se ubica por encima de los niveles de El Salvador, Argentina y México según el coeficiente de Gini. Ha aumentado la brecha entre los ricos y los pobres; mientras las familias más pobres reciben $\mathbb{W} 150.000$ o menos para subsistir al mes, los grupos familiares altos disponen de 4 a 7 millones mensuales (PEN, 2013, p. 103). La creciente disparidad de los ingresos entre 1988 y 2015 pasó de 0,358 a 0,516, de acuerdo con el coeficiente en mención (Molina y Palmer, 2017, p. 173).

En opinión de Carlos Sojo, pese a que actualmente la desigualdad no tiene parangón con otros períodos históricos; el promedio de la población se asume a sí misma como clase media, tal y como lo hace ver una servidora doméstica de origen nicaragüense:

...yo digo que estoy en, digamos, la clase media, porque aunque nosotros vivamos enjaranados y de todo, pues gracias a Dios no sé, en la casa no se vive mal, ellos tienen de todo, lo principal, pues el techito que ahí se va pagando (Sojo, 2010, p. 128).

El hecho de poder pagar las cuentas pendientes y disponer de un techo donde se resida, se convierten en elementos que de acuerdo con esta trabajadora, son indicadores de pertenecer a la clase media. Esta valoración es producto de la autopercepción que concibe a los sectores medios como un estrato ubicado en medio de los pudientes y de los menesterosos:

Actualmente la situación económica de mi papá y mi mamá, bueno de la familia en sí, se puede decir que es buena. O sea no estamos ni muy ricos- 
ISSN 1659-3316

Agüero García Javier

ricos, ni pobres-pobres. O sea más o menos ahí estamos pasándola como dicen (Sojo, 2010, p. 128).

Este es el criterio de una niña proveniente de una región semi-rural que define con "pasarla" a un estilo de vida diferenciado y compartido por quienes viven en la opulencia y del de los que sobreviven en condiciones de miseria.

Los testimonios anteriores se ubican en un punto clave: la población se imagina a sí misma como habitante de un país de clases medias. Aparentemente el hecho de sentirse como parte de los sectores medios es una aspiración heredada, anclada en un mítico imaginario colectivo, y casi que preexiste a la implementación del proyecto político socialdemócrata desarrollado a partir de 1950 (García, 2014, pp. 404-405). Todavía esta forma de autopercepción elaborada más de medio siglo atrás, tiene un peso significativo. Al respecto se puede sugerir que el modelo de desarrollo socioeconómico anterior se resiste a morir, al menos en el plano de una identidad imaginada y compartida, forjada al calor de la movilidad social ascendente.

La fragmentación de las clases medias está asociada a un fenómeno dual: por un lado, se ha experimentado el ascenso de un próspero sector vinculado a la neo-exportación, a la banca privada y a la alta gerencia; grupos sociales privilegiados en el nuevo modelo económico en actividades que en opinión de Juan Diego Trejos, citado por Mylena Vega, “...podrían estar generando formas de riqueza que por su magnitud y patrones de ostentación, no han sido las tradicionales." (Vega, 1996, p. 134). Por otro lado, las capas inferiores -por cierto más numerosas que las primeras- han visto su condición amenazada, producto de las políticas resultantes del ajuste puesto en marcha en las últimas dos décadas del siglo pasado (Mora y Pérez, 2009, p. 10).

Según Carlos Castro (1995), en lo que respecta a los profesionales como integrantes de los sectores medios, han sufrido una pérdida de su seguridad socio-política y un deterioro en las garantías y estabilidad de sus puestos,

\section{(c) (i) (2) (2)}

La Revista Estudios es editada por la Universidad de Costa Rica y se distribuye bajo una Licencia Creative Commons Atribución-NoComercial-CompartirIgual 3.0 Costa Rica. Para más información envíe un mensaje a 
Los sectores profesionales han visto perder su posición económica frente a otros grupos ocupacionales, pues se ha reducido la relación entre su salario promedio y el de los trabajadores no calificados (Castro, 1995, p. 25).

Mientras tanto, la fragmentación también se evidencia en la creciente elitización del sector superior y en la segregación residencial que salta a la vista de cualquier observador que se detenga a mirar el nivel de consumo de quienes habitan esas viviendas de lujo, capaces de adquirir artículos suntuarios, típicos de un sector medio alto, ganadores en definitiva de las políticas de apertura económica patrocinadas por el Estado. La segregación, caracterizada por los barrios amurallados, ha constituido la expresión más acabada de la concentración habitacional de espacios, en función de un nivel socioeconómico caracterizado por un acceso restringido a los recursos colectivos o públicos, todo dentro de la lógica del rechazo doble de compartir y de coexistir (Séguin, 2006, pp. 15-18).

Abundan los anuncios publicitarios a todo color, impresos en folletos y en gigantescas vallas, portadoras de patrones de ostentación muy particulares que muestran, a vista y paciencia de toda la ciudadanía, las bondades de residir en cierto tipo de residenciales y condominios en virtud de sus prestaciones: "seguridad 24/7" (vigilancia veinticuatro horas los siete día de la semana), áreas comunes de esparcimiento y de diversión (gimnasio, piscina y rancho BBQ); todo esto dentro del entorno privado de las instalaciones. Son valores agregados que se asocian a un estilo de vida propio de los grupos exitosos, quienes pueden mantener un nivel de consumo acorde con las demandas de un perfil socioeconómico esmerado en ostentar de lo que posee.

En contraposición al estilo de vida de los triunfadores, los segmentos más pobres residen en conjuntos habitacionales subsidiados por el Estado, mediante la política del bono de vivienda, a partir de la creación del BAHNVI. Su ubicación desborda la histórica sección sur de la ciudad de San José, donde tradicionalmente se han asentado los sectores populares de la urbe. Estos asentamientos se han desarrollado en otros espacios como Pavas y La Uruca; y

La Revista Estudios es editada por la Universidad de Costa Rica y se distribuye bajo una Licencia Creative Commons Atribución-NoComercial-CompartirIgual 3.0 Costa Rica. Para más información envíe un mensaje a 
desde luego, también se hacen presentes en las otras provincias del país. Algunos de ellos comparten los espacios, por la proximidad geográfica, con los precarios en diferentes grados de integración. Dentro de esta distribución socio-geográfica el Estado ha cumplido una acción clave en la consolidación de formas de segregación (Pérez, 2006, pp. 174-175).

\section{Exclusión social}

En términos agregados, durante el lapso de implementación de las políticas neoliberales, algunas instituciones del Estado han reducido sus capacidades de incidencia de nuevos programas dedicados a la salud, la educación y la protección social de los sectores desfavorecidos" (Molina y González, 2015, p. 263).

Por consiguiente, la exclusión como resultado social de la implementación de políticas públicas, tiene una vinculación directa con el grado de bienestar de la población. Pese a que Costa Rica ha sido líder en Latinoamérica, se ha vuelto una tarea difícil recuperar los niveles de inversión por persona de finales de la década de 1970. Esto se ha traducido en el deterioro de las prestaciones universales como salud y educación; aspectos que unidos conducen a la desmejora de la equidad social (Sojo, 2010. pp. 86-87). A su vez, tienen eco en el deterioro de la calidad de vida y, por supuesto, en el descenso del Índice de Desarrollo Humano; Costa Rica en 2016 cayó al lugar 66, después de que en 2003 ocupara el puesto 42 (Boeglín, 2017, p. 1).

Dentro de un horizonte más amplio, la coyuntura heredera del ajuste se caracterizó por la aparición de un nuevo tipo de pobres, quienes pese a que han logrado superar sus ingresos mínimos, no son capaces aún de hacerle frente a necesidades básicas como el vivir sin hacinamiento, mantener a sus hijos en el sistema educativo o contar con agua potable y un servicio sanitario. Según Carlos Sojo (1997), las condiciones de vida de este grupo que empezó a engrosar el sector de los nuevos pobres, son las siguientes.

\section{(c) (i) (2) (2)}

La Revista Estudios es editada por la Universidad de Costa Rica y se distribuye bajo una Licencia Creative Commons Atribución-NoComercial-CompartirIgual 3.0 Costa Rica. Para más información envíe un mensaje a 
- Habitan en las cercanías de la periferia de las ciudades, a menudo sus casas se asemejan a las del precario, en medio de un contexto de marginalidad. Para conseguir su sustento diario, gran parte de ellos cuentan con empleos informales.

- Viven el día a día, e incluso en el caso de que puedan satisfacer una necesidad determinada, automáticamente, se crea otra. El ejemplo más representativo es la obtención de una casa de interés social; en razón de que para poder terminar su construcción (v.g. paredes divisorias y cielos rasos) se requiere de dinero adicional que muchas veces no se posee.

- Técnicamente, se ubican dentro de una condición de pobreza recurrente; esto es, que no están arriba ni abajo de la línea de pobreza. Es un amplio sector social producto de los desplazamientos de un segmento de los que menos tienen y más necesitan.

- En sus hogares, los niños y jóvenes asisten a centros educativos recién fundados en condiciones muy precarias en sus respectivas comunidades. La infraestructura es deficitaria y la permanencia en las aulas es reducida en los planteles, dado que operan con jornadas de tres turnos. Estas características ponen en desventaja a quienes reciben clases allí frente a los escolares y colegiales de centros de enseñanza más antiguos con horarios más extendidos.

- Estas familias carecen de recursos; por eso han optado por adquirir el vestido solo en Navidad. Además la recreación es poco frecuente por el costo económico demandado. Las familias prefieren destinar el poco dinero a la alimentación, que en este caso es básica, incluye prioritariamente el arroz y los frijoles.

- En muchas ocasiones, hogares no son sujeto de la ayuda estatal puesto que se mueven en una "zona gris", que envuelve a la línea de pobreza. Se ubican al margen de las políticas sociales.

\footnotetext{
(c) (i) (2) (2)

La Revista Estudios es editada por la Universidad de Costa Rica y se distribuye bajo una Licencia Creative Commons Atribución-NoComercial-CompartirIgual 3.0 Costa Rica. Para más información envíe un mensaje a revistaestudios.eeg@ucr.ac.cr.
} 
ISSN 1659-3316

Agüero García Javier

Dentro de un horizonte más amplio, la exclusión social está íntimamente relacionada con la desigualdad; considerada como un proceso de gran trascendencia histórica, junto con la pauperización de los sectores medio bajos y el ensanchamiento estructural de una franja de población compuesta por hogares con carencias materiales, no indispensables en el modelo de acumulación capitalista imperante, porque son consumidores "defectuosos" que no logran insertarse dentro del proceso dinámico del capitalismo en tanto no compran no suficiente y tampoco su aporte como productores es significativo (Pérez, 2012, p. 7; Mora y Pérez, 2009, p. 8).

Los excluidos son los que reciben las migajas del total del ingreso total, y los que además, no son atendidos por las políticas públicas; su cantidad varía de acuerdo con la medida empleada por el ente institucional decidido a realizar un conteo de las personas que viven en esas condiciones tan deplorables, en vulnerabilidad o de "desastre social" (Pérez, 2012, p.15). Aunque en Centroamérica los mayores grados de exclusión se centran en el norte del istmo (PEN, 2008); en Costa Rica en 2015 el INEC calculó que el $21,7 \%$ de la población vive en estado de pobreza -317.660 hogares que representan una cuarta parte de la población nacional- además el 7,2\% equivalente a 374.185 personas subsiste en condiciones de pobreza extrema (Leitón y Ramírez, 2015). En el caso hipotético de que se pudiera remunerar con el salario mínimo a personas que están por debajo de éste; se podría reducir el nivel de pobreza en cuatro puntos porcentuales (PEN, 2015b, p. 91). La pobreza se asienta en los sectores más vulnerables: a) se asocia al género porque una importante parte de esa población que vive por debajo de la línea de pobreza, está integrada por familias en donde las mujeres son jefas de hogar: 4 de cada 10 familias pobres son dirigidas solo por mujeres, cuyo número de núcleos familiares se duplicó entre 1987 y 2013 (Rivera, 2014). b) También una buena parte de los pobres (más de 90.000 personas) lo integran adultos mayores que viven brindando sustento a sus hijos y nietos; o

\section{(๑) $\odot \odot$}

La Revista Estudios es editada por la Universidad de Costa Rica y se distribuye bajo una Licencia Creative Commons Atribución-NoComercial-CompartirIgual 3.0 Costa Rica. Para más información envíe un mensaje a revistaestudios.eeg@ucr.ac.cr. 
solos sin el acompañamiento de sus familias (Robles, 2008, pp.12 y subsiguientes).

En todos los posibles escenarios de exclusión hay un factor común: quienes viven en esa condición no disfrutan de los mismos derechos en procura de una vida digna como la salud y la educación, garantizados en la prosa constitucional. La ciudadanía de la que ellos forman parte es limitada; dista en demasía del manto común que cobija al resto de los habitantes, porque tienen un nivel de acceso restringido a las oportunidades de trabajo debido, en gran medida, a su escasa preparación técnica o profesional. En materia habitacional, muchos de ellos viven en precarios, que desde la década de 1980 han clamado desesperadamente por intervención de las instituciones estatales. Algunos de estos asentamientos, construidos en sitios de alta vulnerabilidad ambiental, fueron bautizados por sus mismos ocupantes, con el nombre de un familiar directo de las personas a cargo del gobierno a fin de llamar su atención: en Hatillo, "Los Nietos de Carazo", alusivo al período gubernamental de 1978-1982; en Tirrases de Curridabat, "Gloria Bejarano" en nombre de la señora esposa de Rafael A. Calderón F. (1990-1994); y en honor a Óscar Arias (1986-1990), en barrio Cristo Rey, "Premio Nobel" y en Heredia, "Lilliam Sánchez", en alusión a la madre del mandatario.

Lo anterior encuentra una razón en el "uso político de la pobreza"; los candidatos a la presidencia de la República se esmeran en las campañas políticas en poner en entredicho las acciones del gobierno de turno frente a la población más vulnerable de la sociedad. Según ellos, de resultar ganadores mejorarían las condiciones de los más pobres. No obstante, como en reiteradas oportunidades, estos ofrecimientos durmieron el sueño de los justos, los habitantes de los precarios optaron por recordar a su candidato, ahora presidente de la república, por medio de las denominaciones tan particulares de estos tugurios.

\section{(c) (1) (2)}

La Revista Estudios es editada por la Universidad de Costa Rica y se distribuye bajo una Licencia Creative Commons Atribución-NoComercial-CompartirIgual 3.0 Costa Rica. Para más información envíe un mensaje a 


\section{Los diferentes rostros de la exclusión}

La exclusión suele acompañarse de factores como la baja calidad educativa, y el desempleo, característicos de la vulnerabilidad social. Sus generalidades se exponen a continuación.

- La educación por excelencia se ha concebido como uno de los vehículos de movilidad social, porque el proceso de escalar los distintos niveles del sistema educativo mejora la probabilidad de no permanecer en la pobreza (Arias, Sánchez y Giménez, 2016, p. 43). Si las personas logran concluir sus estudios secundarios pueden mejorar su condición socioeconómica. Sin embargo, en un entorno donde coexiste un sistema masivo público con uno privado minoritario, la educación ha empezado a perder está función; y en su lugar, ha pasado a cumplir otra: la profundización de las diferencias sociales. De acuerdo con Kattya Grosser, (2012)

La escuela pública de la modernidad se erigió sobre el principio de igualdad pero, en la actualidad, este principio como condición de posibilidad es una farsa, pues, para empezar, existe una brecha enorme entre la educación pública y la privada, no solo en los procesos formativos y contenidos que transmiten, sino en la significación de la misma en el proyecto futuro de quienes logran graduarse. [...] Por otra parte, la educación privada y las posibilidades que brinda para sus graduados es, por mucho, muy superior a la que pueden ofrecer las instituciones públicas (p. 207).

En lo que respecta al nivel de aprobación del ciclo diversificado, para noviembre de 2014, según datos de la Oficina de Gestión y Evaluación de Calidad del MEP, solo los estudiantes de un $16 \%$ de los colegios, entre públicos y privados obtuvieron un resultado de aprobación en todas y cada una de las asignaturas evaluadas en el examen de bachillerato. Además, se registraron resultados

\section{(c) (i) (2)}

La Revista Estudios es editada por la Universidad de Costa Rica y se distribuye bajo una Licencia Creative Commons Atribución-NoComercial-CompartirIgual 3.0 Costa Rica. Para más información envíe un mensaje a 
deplorables en 31 centros de enseñanza en donde ningún estudiante logró graduarse de bachiller de secundaria (Oviedo, 2015).

- Estos datos están íntimamente relacionados con la diferenciación de los resultados según sean las áreas geográficas con rezago, a saber, rural y urbana; en las primeras se destacan los casos de Talamanca, Limón y la zona Sur o peor aún: las calificaciones también tienden a ser más bajas en zonas urbano marginales como Desamparados y Alajuelita (Arias, Sánchez, y Giménez, 2016., pp. 41-43). La exclusión educativa, con sus consiguientes efectos sobre el empleo, golpea con más severidad a las direcciones educativas de Grande de Térraba, Aguirre, Coto y Sarapiquí (Araya, 2017; PEN, 2015a, pp. 299 y subsiguientes).

- La misma cobertura de la educación superior también se ha concentrado en el valle Central; mientras los cantones costeros y fronterizos viven una situación desfavorable, la mayoría cuentan con una calificación de 50 en el ítem correspondiente al acceso a la educación universitaria (PEN, 2015a, p.198).

- Estas debilidades intrínsecas han dado como resultado las dificultades propias de la falta de inserción de los jóvenes en el mercado laboral por carecer de calificación necesaria. Estas falencias del sistema contribuyen a explicar el caso de los "ninis", jóvenes y adultos jóvenes entre 15 y 24 años que no estudian ni trabajan, su cantidad se calcula para 2016 entre los 150.000 y 172.000 (Chinchilla, 2016). Los jóvenes entre los 15 y los 24 años también son duramente golpeados porque en ese segmento etario se ubica el $45 \%$ del total de las personas sin empleo (Leitón, 2015).

- El desempleo y el subempleo, junto con la informalidad del empleo, son indicadores que dicen mucho acerca de la exclusión social; porque quienes se encuentran en esas condiciones, no son incluidos en el sistema de seguridad social. En el resto del área centroamericana, los indicadores son desalentadores;

\section{(@) $\odot \odot$}

La Revista Estudios es editada por la Universidad de Costa Rica y se distribuye bajo una Licencia Creative Commons Atribución-NoComercial-CompartirIgual 3.0 Costa Rica. Para más información envíe un mensaje a revistaestudios.eeg@ucr.ac.cr. 
en su conjunto, pasó de tener una incidencia del 36\% al 42\%, entre 2009 y 2014 (PEN, 2016, pp.135 y subsiguientes). En Costa Rica el desempleo se calcula en casi un diez por ciento de la PEA, según datos del primer semestre de 2015; las mujeres son las que llevan la peor parte; junto con las personas que poseen alguna discapacidad, población con un 54\% de la gente en paro, siete veces mayor que el promedio nacional (Barrantes, 2013).

- En su conjunto, la gran mayoría de estas personas no tienen la calificación esperada para colocarse en un empleo. En cuanto al subempleo, se carece de una cifra oficial que pueda englobarlo; sin embargo, lo más alarmante es que éste, junto con el empleo informal, han sido los rubros en crecimiento en las últimas décadas; en su mayoría están conformados por personas dedicadas al trabajo por cuenta propia que no cotizan para el régimen de seguridad social del país. Se calcula que esta modalidad de ganarse el sustento concentra el $41 \%$ de la masa laboral (Rodríguez, 2016, p. 4-5). Su gama es muy amplia: va desde el vendedor de flores en las intersecciones viales, hasta el ingeniero quien labora por cuenta propia, remunerado a destajo por concepto de servicios profesionales, a cambio de supervisar las obras de un lujoso hotel de playa; pasando por la servidora que prepara perros calientes en una soda improvisada.

- Las regiones periféricas concentran condiciones desfavorables con respecto a la GAM, donde se acentúan la pobreza, la falta de oportunidades de empleo y la baja escolaridad. Conforman este conglomerado las regiones Huétar Atlántica, Huétar Norte, Chorotega y Brunca. La condición de informalidad es más que evidente en las regiones Huétar Norte y Brunca: un 56 y un 57\%, en su orden respectivo (Rodríguez, 2016, p. 4-5). No es fortuito entonces que en una región como la Brunca el nivel de incidencia de pobreza sea superior al promedio nacional, en 2009 alcanzó un 30,9\% (Morales, 2011, p.152). 
En este contexto de desigualdades regionales crecientes, los cantones de Guanacaste no son el mejor ejemplo de acceso a oportunidades ni de desarrollo, su IDH es bajo. De ahí que, en julio de 2007, una joven doce años, estudiante de la Escuela Rural de Zaragoza de Nicoya, alzó su voz en el acto protocolario conmemorativo de la Anexión del Partido de Nicoya y se refirió a los presentes, entre ellos a los miembros de los supremos poderes de la República. Sus palabras, que enfadaron al señor presidente de la república, se transcriben a continuación.

\section{Gritos de la pampa}

De las bajuras vengo y traigo en el puro cacaste la cepa de nicoyano y el espíritu de Guanacaste.

Como llanero de cepa sé de angustias y tristezas, de la gente humilde de esta Pampa Guanacasteca.

Por los tiempos de julio me agarra la pensadera, si la mentada anexión no fue pura reculadera.

Es que la pura verdad, ya sin pelos en la lengua Guanacaste con todas sus grandezas, atilinta penas, miserias y tristezas.

$[\ldots]$

Y pa'qué desarrollo turístico, si las empresas no son de los guanacastecos y si además a la mayoría del pueblo, no le sobra la plata, para fachentear como turistas en los hoteles cercanos al mar.

Guanacaste, Guanacaste, provincia que se anexó a Costa Rica por su propia voluntad, es un paraíso natural que despierta la codicia del imperialismo.

Antes el latifundismo, luego la explotación del criollo en las minas y haciendas ganaderas, ahora la explotación turística, absorbida por la inversión extranjera.

$[\ldots]$

Desde la anexión, recibes trato inmerecido, mansillándote en cada 25 de julio, con discursos floridos llenos de promesas y proyectos no cumplidos,

\section{(C) $(00$}

La Revista Estudios es editada por la Universidad de Costa Rica y se distribuye bajo una Licencia Creative Commons Atribución-NoComercial-CompartirIgual 3.0 Costa Rica. Para más información envíe un mensaje a 
mientras el pueblo sigue jodido viviendo en tugurios y empobrecido.

Despierta hermano guanacasteco, despierta tu espíritu indómito, suéltate el bozal, quítate la talmeca, demuestra tu coraje y altivez Chorotega, toma las riendas del potro chúcaro y domina el toro cimarrón del imperialismo, luego rájate tus bombas y retahílas, como un reto lleno de hombría y bailando alegres la yegüita, nos vamos a tomar chicheme a La Cofradía.

¡Hey, bajuras húmedas, carajo!

Viva Guanacaste, viva nuestra provincia.

Vivan los cantones de la altura y vivan los cantones de la bajura (Espinoza, 2007, p. 6)

Como sucedió en Zaragoza de Nicoya, el agravamiento de la exclusión en las regiones periféricas explica que en febrero de 2018 gran cantidad de población ahí asentada le brindó un masivo apoyo electoral a una fuerza política que apenas había colocado un legislador en una curul para el período 2014-2018. Fabricio Alvarado, el candidato de Restauración Nacional logró aglutinar, gracias a su estrecha relación con las iglesias neopentecostales, una importante base de respaldo en esas zonas geográficas que por definición concentran gran presencia de templos evangélicos, donde muchas veces estas agrupaciones han asumido el papel de un Estado ausente incapaz de incidir en la mejora de la calidad de vida de sus habitantes. En el caso particular de Limón, pobladores recibieron la ayuda en víveres y reconstrucción de viviendas por parte de agrupaciones religiosas frente a los duros embates de la Tormenta Nate ocurrida en 2017 (Bosque, 2018, p. 4-5 A).

En la primera ronda, Fabricio Alvarado obtuvo el apoyo de veintitrés de los veintiocho cantones ubicados en las costas, además de los seis cantones limonenses. Era la respuesta ante la realidad de desigualdad que incide en la calamitosa situación socioeconómica que agobia a la mayoría de sus habitantes. De alguna manera este comportamiento se interpreta como un reclamo ciudadano

\section{(C) $(\Theta \odot \odot$}

La Revista Estudios es editada por la Universidad de Costa Rica y se distribuye bajo una Licencia Creative Commons Atribución-NoComercial-CompartirIgual 3.0 Costa Rica. Para más información envíe un mensaje a 
al PAC como partido oficialista, mediante el voto protesta; y consiguientemente al decidido respaldo a una opción política más próxima, en la que los habitantes de las costas y de las fronteras ven una solución a sus necesidades con el "voto esperanza" (París, 2018, p. 20 A). Ante esta desatención por parte de las instituciones, Isabel Román llama la atención en los términos siguientes: “...no atender problemas graves identificados con celeridad que el país requiere, puede llevarnos a situaciones cada vez más complicadas y con mayores costos sociales, económicos y políticos" (Román, 2018, p. 22 A).

\section{Movimientos sociales}

Las diferentes reacciones de los grupos sociales a partir de la puesta en ejecución de las medidas de corte neoliberal por parte de los gobiernos están vinculadas con el ajuste macroeconómico y con los procesos concomitantes, conducentes a una redefinición de la acción estatal. En su conjunto, han constituido todo un campo de investigación por parte de quienes se encargan del análisis social. En este caso en particular, se trata de identificar los móviles concretos de estos movimientos, además de dilucidar las conquistas -si las huboluego de terminada una huelga o protesta.

La evolución histórica de los movimientos sociales viene desde tiempo atrás; casi se puede datar y afirmar con algún sentido de propiedad, que llegaron a adquirir relevancia hacia la década de 1920, cuando emergieron jornadas de protesta, integradas por grupos determinados como zapateros y panaderos, portadoras de reivindicaciones en favor de condiciones dignas de trabajo (Acuña, 1984). Luego, un punto álgido de esta evolución de la efervescencia social, lo conformó la coyuntura de la década de 1940 cuando los sindicatos, el Partido Comunista y el gobierno de entonces, marcharon juntos por las calles josefinas en compañía del jefe de la iglesia católica: Monseñor Víctor Sanabria. Estos tres

\section{(๑) $\odot \odot$}

La Revista Estudios es editada por la Universidad de Costa Rica y se distribuye bajo una Licencia Creative Commons Atribución-NoComercial-CompartirIgual 3.0 Costa Rica. Para más información envíe un mensaje a 
sectores celebraron al unísono la promulgación del capítulo de Garantías Sociales en 1943.

Para los años setenta se experimentó un auge en el sindicalismo, se rubricaron convenciones colectivas en el sector público y privado (Aguilar y Ramírez, 1989, pp. 64-65). En la década siguiente empezó un proceso caracterizado por el desgaste progresivo de los sindicatos del sector privado al punto que el más combativo de todos, el bananero, tiempo después recibió una estocada mortal a propósito de la huelga, desatada en 1984, contra la compañía frutera establecida en el Pacífico (Aguilar y Ramírez, 1989, pp. 189 y subsiguientes). Todo esto ocurrió mientras paralelamente, los gobiernos estimulaban el solidarismo, impulsado por Alberto Martén, una figura muy cercana al dos veces presidente constitucional de Costa Rica, José Figueres Ferrer, como estrategia para combatir las reivindicaciones de la clase trabajadora: era la época del anticomunismo resultante de la guerra civil de 1948 (Barrientos, 2015, pp. 94 y subsiguientes). Además la cúpula del PLN tomó medidas a fin de cooptar el movimiento popular que clamaba por soluciones de vivienda desde los años cincuenta hasta fines de los ochenta. El producto de este largo proceso no se hizo esperar: sobrevino una minimización del sindicalismo; en la actualidad sobrevive a duras penas, en el sector de los servidores públicos; espacio donde, como lo dispone el ordenamiento jurídico, se han firmado convenciones colectivas: acuerdos signados con rango de ley ente el patrono y los empleados. En tiempos recientes éstas son duramente cuestionadas por sectores políticos y empresariales.

Entre 1980 y 1995 se puede identificar una primera etapa marcada por las luchas constantes de las personas organizadas en torno a las protestas por el alza en las tarifas de los servicios públicos. Los años ochenta se caracterizaron también por la negativa de cancelar el monto por concepto de electricidad por parte de los abonados de la Compañía Nacional de Fuerza y Luz. Como señal de descontento, en ventanas de las casas lucían carteles pegados que decían: "yo no 
ISSN 1659-3316 Agüero García Javier

pago la luz" Alvarenga, 2005, pp.117 y subsiguientes). Otras protestas se organizaron frente a la negativa de los empresarios, dueños de los autobuses; como sucedió con a empresa Metrocoop, cuando los usuarios comenzaron a sentirse molestos por el pésimo servicio de buses prestado por los propietarios del consorcio cooperativo (D'Alolio, 2007, pp. 185-188). En otras ocasiones los vecinos llegaron al límite de hastío por las irregularidades e incumplimientos sucesivos, tomaron la justicia en sus manos y en más de una oportunidad, no dudaron en dirigirse al plantel de los buses en horas de la madrugada y prenderle fuego a las unidades; esto como protesta del deficiente servicio prestado a los usuarios. En su conjunto, la intensificación de las manifestaciones combinó huelgas y bloqueos; en junio de 1983 el país amaneció paralizado. A fin de resumir las principales reivindicaciones de los diferentes sectores sociales se presenta el cuadro 1.

\section{Cuadro 1 \\ Principales reivindicaciones por parte de los diferentes sectores sociales}

\begin{tabular}{|c|c|}
\hline & (198) \\
\hline Tipo de demanda & Descripción \\
\hline Agua & $\begin{array}{l}\text { Al igual que las manifestaciones en contra de la electricidad fueron } \\
\text { resultado del aumento tarifario. Tendieron a bajar su tono hacia } \\
1986 \text {. }\end{array}$ \\
\hline $\begin{array}{l}\text { Alimentación y } \\
\text { nutrición }\end{array}$ & $\begin{array}{l}\text { Fueron crecientes a lo largo del período y clamaban por ayuda en } \\
\text { medio de un contexto de pauperización. }\end{array}$ \\
\hline Educación & $\begin{array}{l}\text { Constantes durante todo el período. } \\
\text { Protagonizadas sobre todo por los universitarios que pedían } \\
\text { presupuesto para sus casas de estudio. }\end{array}$ \\
\hline Electricidad & $\begin{array}{l}\text { Aglutinaron el descontento urbano ante el incremento de las tarifas } \\
\text { eléctricas, su agitación llegó a su clímax en } 1983 .\end{array}$ \\
\hline Salud & $\begin{array}{l}\text { Con un comportamiento variable en el tiempo. Fueron portadoras de } \\
\text { la oposición a la privatización a las clínicas de la CCSS. }\end{array}$ \\
\hline Transporte & $\begin{array}{l}\text { Cobraron visibilidad en } 1982 \text { y se hicieron más frecuentes al final de } \\
\text { la década de los ochenta. }\end{array}$ \\
\hline Vivienda & $\begin{array}{l}\text { En una primera fase (1982-1986) fueron más intensas. Luego } \\
\text { tendieron a disminuir por la acción del gobierno de Arias (1986-1990). }\end{array}$ \\
\hline
\end{tabular}

Fuente: Elaboración propia basada en Trejos, María Eugenia y Valverde José Manuel. (1993). "Diez años de luchas urbanas en Costa Rica 1982-1992". Revista de Ciencias Sociales, (61) pp. 9-10.

\section{(c) () (ㅇ)}

La Revista Estudios es editada por la Universidad de Costa Rica y se distribuye bajo una Licencia Creative Commons Atribución-NoComercial-CompartirIgual 3.0 Costa Rica. Para más información envíe un mensaje a revistaestudios.eeg@ucr.ac.cr. 
En 1990, luego de un destacado desempeño de la Selección Nacional de Fútbol en el Campeonato Mundial en Italia, pese a que el gobierno entrante de Rafael A. Calderón -el primero del PUSC- había cimentado sus promesas de campaña política en el apoyo de los sectores más vulnerables de la sociedad, dio inicio a un violento proceso de aplicación de medidas neoliberales (terapia de shock) con la reducción del 17 al 15\% del PIB en los rubros correspondientes a la salud, educación y vivienda con el consiguiente aumento en el nivel de pobreza que cerró en un $32 \%$ al cabo del primer año de gobierno. Los sectores populares contestaron con 89 huelgas y paros entre 1990 y 1993. Esta estrategia de algo impacto, conducente a la implementación del tercer PAE fue superada en intensidad durante la administración siguiente (Molina y Palmer, 2017, p. 154).

Una segunda etapa, inició a partir de los hechos de 1995, cuando se vivió uno de los capítulos más trágicos de esta historia social; debido al trago amargo que dejó a su paso la huelga del magisterio nacional. Los docentes dejaron las aulas, tomaron las calles y marcharon por la defensa de su régimen de pensiones; que según los políticos de turno ameritaba una cirugía mayor en razón de su insostenibilidad. La huelga se prolongó entre junio y agosto; las movilizaciones fueron en aumento y hubo agresiones por parte de los cuerpos de seguridad, a su vez entrenados por carabineros chilenos (Molina y Palmer, 2017, p. 157). El final del movimiento trajo consigo un muy mal sabor de boca debido a que en una madrugada los dirigentes sentados en la mesa de negociaciones claudicaron, con un cierto hálito de elegancia, en favor del gobierno. A partir de aquí, las lecciones, otrora suspendidas, se empezaron a restablecer paulatinamente, luego de semanas enteras de huelga y después de que a algunos educadores se les hiciera efectivo el rebajo salarial.

Las consecuencias de esta huelga fueron claras; y probablemente, la más inmediata de todas, radicó en la reforma del régimen de pensiones realizada por el legislativo contra viento y marea; plasmada en una nueva ley (la 7539) que recortaba los beneficios de su predecesora. Los grandes perdedores fueron los 
trabajadores de la educación quienes vieron con encono lo sucedido; al mismo tiempo que empezaron a mirar con resabio las políticas implementadas por los partidos políticos mayoritarios ahora coaligados en el "PLUSC" (Raventós, 2018, p. 157). Con la nueva ley, los educadores tendrían que laborar por más años a cambio de una pensión porcentualmente menor. Esta reforma formaba parte de los objetivos del pacto Figueres-Calderón, celebrado en abril de 1995; y que por cierto, contaba entre sus paladines a los grupos empresariales, a los medios de comunicación y a la cúpula de la iglesia católica (Menjívar, 2008, pp. 98-100).

A escasos cinco años después de la derrota de la huelga de los maestros, se empezó a urdir un nuevo proyecto por parte de la clase política, de nuevo orquestado por los dos partidos mayoritarios, su cometido fundamental consistía en aprobar una ley de modernización en telecomunicaciones, como parte de un macro plan de venta de activos estatales. Este proyecto legislativo despertó la desconfianza de los trabajadores del ICE, para quienes todo se resumía en una afrenta clara y directa a la institucionalidad pública que recordaba dos incidentes de ingrata memoria. 1) El de Comcel-Millicom, una empresa transnacional que brindó el servicio de telefonía celular a vista y paciencia de las autoridades de entonces. Al final, el Estado costarricense se vio en la obligación de pagarle a dicha empresa una jugosa cantidad de dinero, luego de que su abogado -uno de los diputados elegido para el período 2014-2018 y candidato presidencial por el PLN en la campaña de 2018-, ganara una causa en favor de la empresa extranjera, esto pese a ser declarado fuera de la ley el actuar de dicho consorcio internacional, por parte de la Sala Constitucional. 2) La reforma legal (Ley de Cogeneración Eléctrica) llevada a cabo durante la administración Figueres Olsen, con un objetivo eminentemente neoliberal de obligar al ICE a comprar la energía a empresarios generadores privados a un costo más alto del que lo producía el mismo ICE.

Alrededor de la causa del ICE, se aglutinaron paulatinamente grupos de una amplia heterogeneidad: maestros y estudiantes; campesinos y amas de casa,

La Revista Estudios es editada por la Universidad de Costa Rica y se distribuye bajo una Licencia Creative Commons Atribución-NoComercial-CompartirIgual 3.0 Costa Rica. Para más información envíe un mensaje a 
entre otros. La movilización alcanzó su punto álgido entre marzo y abril de 2000. Juntos tendían barricadas, efectuaban bloqueos, quemaban llantas y levantaban la voz, cantando al unísono: “ICE sí, Combo no”. Aún así, como había ocurrido con el caso del movimiento en contra de la transnacional Compañía de Aluminio de América (ALCOA) en 1970; el proyecto fue aprobado en la Asamblea Legislativa. El documental El combo callejero, ofrece una imagen clara de cómo en esa Asamblea Legislativa, una señora diputada perteneciente a un partido mayoritario de aquella legislatura, arengaba desde su curul con tono acre y despectivo; refiriéndose a las multitudes participantes de la lucha callejera como personas incultas, incapaces de comprender los designios del futuro; reservando por antonomasia la resolución de dichos asuntos exclusivamente a los dirigentes del Estado. Por otro lado, estos acontecimientos dejan ver como uno de los diputados de bajo perfil -porque no se caracterizaba precisamente por brindar declaraciones con regularidad a la prensa- dio su voto a favor del Combo y resultó luego el ganador de los comicios presidenciales para el período inmediato siguiente iniciado en 2002.

El balance de la lucha contra el Combo, en términos generales, fue positivo para los manifestantes porque el presidente Rodríguez Echeverría, distinguido por profundizar la aplicación de las medidas neoliberales, optó por retirar el proyecto de ley, que era la manzana de la discordia entre sus defensores y sus detractores. Se acabó una lucha al cabo de meses de confrontación social y fracasó, por consiguiente, la política presidencial basada en la "concertación nacional”, su lema de campaña electoral. No obstante es de resaltar que durante los últimos días de gobierno de Miguel Ángel Rodríguez se aprobó una reforma en el artículo 256 bis del Código Penal para sancionar con rudeza a quienes realizasen bloqueos en las calles:

\section{(c) (i) (2)}

La Revista Estudios es editada por la Universidad de Costa Rica y se distribuye bajo una Licencia Creative Commons Atribución-NoComercial-CompartirIgual 3.0 Costa Rica. Para más información envíe un mensaje a revistaestudios.eeg@ucr.ac.cr. 
ISSN 1659-3316

Agüero García Javier

Obstrucción de la vía pública

Se impondrá pena de diez a treinta días de prisión a quien, sin autorización de las autoridades competentes, impidiere, obstruyere o dificultare, en alguna forma, el tránsito vehicular o el movimiento de transeúntes (Código Penal).

Un nuevo capítulo del movimiento social se empezó a escribir a partir de la administración de Abel Pacheco (2002-2006), contra el ingreso de Costa Rica al Tratado de Libre Comercio. Las clases empresariales y políticas empezaron a acariciar la idea de acelerar el envío de dicho tratado al legislativo para así aprobarlo cuanto antes. Empero su suerte no se saldó durante el gobierno socialcristiano iniciado en 2002; esto pese al sinnúmero de presiones recibidas por el mismo Pacheco de la Espriella para que el gobierno posterior, no tuviera que lidiar con la aprobación de un tratado clave para la vida económica y social de Costa Rica. El interés estribaba en que Pacheco entregara la mesa servida a su sucesor con el TLC ya aprobado; sin embargo; pospuso el envío del tratado a la Asamblea Legislativa. Así en 2006, la administración de Óscar Arias tuvo que asumir el desafío de aprobar el tratado en momentos en que el movimiento social empezaba a cerrar filas y a medir fuerzas en aras de impedir su cometido de convertirse en ley de la república; fueron cada vez más frecuentes las manifestaciones y las concentraciones masivas realizadas predominantemente en los alrededores de la Asamblea Legislativa; el Diario Extra en diferentes ocasiones adjetivó en sus titulares como multitudinarios a esos movimientos, cuando el lente de la cámara fotográfica captaba la columna humana que se extendía desde Cuesta de Moras hasta el paseo Colón. Eran sin duda alguna una expresión de una nueva era que auguraba las luchas de resistencia global (Menjívar, 2008, p.102).

Ante la eventual radicalización del conflicto social con la consiguiente escalada hacia posiciones cada vez más polarizadas y difíciles de darles respuesta, a guisa de lo sucedido con el Combo, el gobierno hizo uso de una nueva herramienta para así decidir el futuro del tratado: la convocatoria del primer

\section{(c) (i) (2)}

La Revista Estudios es editada por la Universidad de Costa Rica y se distribuye bajo una Licencia Creative Commons Atribución-NoComercial-CompartirIgual 3.0 Costa Rica. Para más información envíe un mensaje a revistaestudios.eeg@ucr.ac.cr. 
referéndum vinculante en la historia de Costa Rica. Esto luego del rechazo, en un primer momento, de la solicitud realizara mediante una recolección de firmas para que la convocatoria resultase una iniciativa popular, denominada como "propuesta ciudadana" planteada al TSE por parte del excandidato presidencial José Miguel Corrales en compañía de otras figuras vinculadas a la política (Mora, 2016, pp. 217-218).

Así la ciudadanía elegiría, vía voto popular, el domingo 7 de octubre de 2007 entre el sí y el no al TLC. El gobierno de Arias estaba comprometido con el tratado comercial y el presidente en más de una ocasión prometió hasta lo imposible a la ciudadanía, como se ilustra en el documental La tosca herramienta. En la Zona Sur Arias Sánchez ofreció la construcción de un aeropuerto a cambio de los votos en favor del TLC. Luego de una campaña feroz, merced a los raudales de dólares invertidos en la publicidad que ofrecía las más almibaradas promesas para sustituir el viejo automóvil coreano por un suntuoso MercedesBenz, el sí logró salir victorioso del envite con un margen muy estrecho a su favor, y de paso, se frustró la posibilidad de resolver el asunto en las calles. No obstante, la polarización de las posiciones en liza dejó a un país dividido cuyos efectos aún pueden percibirse. En primera instancia, los comités patrióticos, células de acción opositoras al TLC, se desgranaron casi inmediatamente de la victoria del sí, ante la amargura de la derrota. En segundo plano, no hubo posibilidad de la conformación de una tercera fuerza política capaz de rivalizar con el bipartidismo tradicional, pues luego de la experiencia de la pérdida se abortó cualquier intento de cohesión posterior a nivel partidario (Raventós, 2018).

\section{La toma de las calles, una forma de vivir la política}

El sistema democrático representativo y el complejo entramado de la institucionalidad misma de Costa Rica ha dejado deudas sin saldar con la ciudadanía, en gran medida porque la dirigencia política no han dado cuentas de

\section{(c) (i) (2)}

La Revista Estudios es editada por la Universidad de Costa Rica y se distribuye bajo una Licencia Creative Commons Atribución-NoComercial-CompartirIgual 3.0 Costa Rica. Para más información envíe un mensaje a revistaestudios.eeg@ucr.ac.cr. 
lo ocurrido, cuando se les interroga, acerca de temas como las razones que mediaron en el interés de aprobar proyectos como la reforma del sistema de pensiones del Magisterio Nacional, o bien el de modernización eléctrica y de telecomunicaciones. Las justificaciones vinieron del frente de los tecnócratas, especializados en ofrecer explicaciones no aptas para el público de a pie, porque según ellos, la gente corriente no es capaz de entender el teje y maneje de temas tan complejos; de ahí se determinó en la práctica que es el grupo empresarial bien vinculado con políticos, el único autorizado por su especialización, a decidir. Este típico discurso de razonamiento de los tecnócratas tuvo sus paladines a partir de la administración de Figueres Olsen, muy visible con el caso del Combo ICE durante la administración de Miguel Ángel Rodríguez y, desde luego en el segundo cuatrienio de gobierno de Arias Sánchez con ocasión del TLC.

Frente a este panorama, Sindy Mora (2016) indica que el movimiento social tomó la iniciativa de lanzarse a las calles -una acción ya empleada en décadas anteriores- a fin de impedir a toda costa la aprobación de leyes nocivas para la colectividad. A continuación se indican las características de estas formas de manifestación social.

- Son visibles desde la huelga de los educadores en 1995, las protestas contra RITEVE en 2004, la lucha contra el Combo del ICE y el conjunto de acciones desplegadas contra el TLC. Constituyen capítulos de la política de la calle, integradas por personas que reclaman algo más allá de lo ofrecido por el sistema democrático formal basado en emitir el voto cada cuatro años.

- Los espacios comunales como las ferias del agricultor, las iglesias y las universidades públicas conforman sitios de encuentros políticos; es la calle donde la gente discute temas de su interés. Pese a que ha existido un desprestigio o estigmatización de las manifestaciones callejeras, los grupos de personas organizadas han incursionado en un terreno diferente al

\footnotetext{
(c) (1)(2)

La Revista Estudios es editada por la Universidad de Costa Rica y se distribuye bajo una Licencia Creative Commons Atribución-NoComercial-CompartirIgual 3.0 Costa Rica. Para más información envíe un mensaje a revistaestudios.eeg@ucr.ac.cr.
} 
enunciado por los canales de la institucionalidad caracterizados por la definición de los cánones enmarcados en las normas preconcebidas. La calle como espacio de interacción va más allá de lo estipulado en las políticas establecidas; allí se urden estrategias que trasciendan el radio de acción de los partidos políticos mayoritarios, ya deslegitimados por los pactos que acostumbran entablar entre ellos mismos circunscritos en un sistema bipartidista anquilosado.

- La política de la calle se ha tenido que enfrentar a la "confluencia perversa" de las cúpulas de los partidos políticos tradicionales como fue el proceso de concertación nacional de 1998 cuyo derrotero más importante lo constituyó el proyecto de ley de apertura del ICE. Otros episodios de esta táctica lo conforman la redacción del "Memorando del miedo", escrito por un vicepresidente de la república y un diputado oficialista; además de la estrategia de violación de la autonomía sindical empleada por la administración de Óscar Arias, cuando en 2010 decidió promover una asamblea alterna diferente a la integrada por el Sindicato de Trabajadores de JAPDEVA (SINTRAJAP). Todo esto para lograr el cometido de concesionar, a manos privadas, los muelles de la provincia de Limón.

- Frente a estas últimas muestras de "autoritarismo tecnocrático" la política de la calle ha resurgido el interés por la política e incluso ha llevado a potenciar una serie de conflictos posteriores al mismo referéndum de 2007; a su calor se han configurado nuevos sectores políticos interesados a hacer frente este autoritarismo por medio de las disputas de los conocimientos. De ahí que en gran medida de estas luchas, que vienen desde abajo, se defienda la autonomía organizativa y la autogestión educativa e informativa (Mora, 2016, pp. 99-104, 156-158, 212-213, 245-246).

\footnotetext{
(c) (i) (2)

La Revista Estudios es editada por la Universidad de Costa Rica y se distribuye bajo una Licencia Creative Commons Atribución-NoComercial-Compartirlgual 3.0 Costa Rica. Para más información envíe un mensaje a revistaestudios.eeg@ucr.ac.cr.
} 


\section{Los movimientos sociales en perspectiva}

Se puede sugerir una comparación entre estos tres movimientos sociales anteriores que levantaron los ánimos y enardecieron los ímpetus en favor de defender algo que consideraban muy suyo: a) en 1995, el sistema de pensiones para disfrutar de una vejez digna para los educadores; b) en 2000, una empresa, patrimonio de los costarricenses, ante la privatización de la energía y de las telecomunicaciones; y finalmente, c) en 2006 y 2007, el interés ciudadano de impedir la ruptura de la institucionalidad con la firma de un tratado comercial que, indiscutiblemente, entre sus cláusulas incluía aspectos que comprometían la soberanía nacional.

En cuanto al nivel de participación se puede visualizar ha ido in crescendo a lo largo de la duración de la protesta. En 1995, los educadores acompañados con contadas agrupaciones sindicales de otros sectores, nutrieron el movimiento huelguístico; sin embargo, conforme pasaron los días degeneró en toda una jornada de desgaste que erosionó paulatinamente los apoyos, ante las amenazas de rebajo de sueldos por parte del señor ministro de Educación, Eduardo Doryan. En tanto, los movimientos de 2000 y 2006-2007, aglutinaron diferentes fuerzas sociales, más allá de los sindicatos y se constituyeron paulatinamente en expresiones asumidas por las personas organizadas en función de objetivos específicos. En esa dinámica se incorporó masivamente a la población; poco a poco, gente que no tenía vínculo directo con la empresa de generación eléctrica, dio su apoyo incondicional al ICE. En el caso del TLC, la causa del no cada vez logró calar más fuerte en los diferentes sectores sociales, antes de suceder el golpe de timón, cuando se sometió a una consulta ciudadana la decisión de firmar el tratado.

En cuanto a los logros, se podría asumir una posición fría en el análisis y afirmar que, en definitiva, solo la lucha en las calles del Combo triunfó; sin embargo, esta aseveración, además de ser categórica, por medir los resultados en

La Revista Estudios es editada por la Universidad de Costa Rica y se distribuye bajo una Licencia Creative Commons Atribución-NoComercial-CompartirIgual 3.0 Costa Rica. Para más información envíe un mensaje a revistaestudios.eeg@ucr.ac.cr. 
términos de absolutos, no está exenta de riesgos. En primer lugar, tanto la huelga de educadores de 1995 como la lucha del no al TLC, fueron frustradas solamente al llegar al final; la primera se perdió en una mesa de negociación en el momento en que, en una madrugada la dirigencia cedió ante las demandas del gobierno; algunos representantes sindicales claudicaron, junto con un rector de una universidad pública. EI TLC, tuvo una suerte similar porque, pese a un cierto nivel de certeza de la victoria del no, éste salió derrotado, en el escrutinio de votos emitidos en el referéndum. Se sugiere entonces, que la lucha contra el tratado en cuestión estaba preparada para darlo todo en la calle, pero a la hora de decidir por medio de la vía institucional, pudo más la voluntad de la ciudadanía votante que creyó en los ofrecimientos de un gobierno abanderado con el sí al TLC. Una posible explicación del desenlace se sugiere por parte de Esperanza Tasies (2015), quien expone las contradicciones y las tensiones existentes entre el Frente Nacional de Apoyo contra el TLC, portador de negociar sin quebrar el orden institucional, y la Coordinadora Nacional de Lucha contra el TLC. El primero, fue al fin y al cabo quien se impuso al segundo, dispuesto a dar la lucha social mediante la movilización (Tasies, 2015, pp. 300-301). Fueron dos formas de organización de los actores sociales que poco a poco decantaron el rumbo de los acontecimientos en virtud de la cooptación de la protesta social resultante.

En segundo lugar, en la línea de organización de los movimientos sociales, se pueden trazar algunos puntos de continuidad entre las luchas contra el Combo y el TLC. Al respecto, véase el cuadro 2.

\section{(c) (i) (-)}

La Revista Estudios es editada por la Universidad de Costa Rica y se distribuye bajo una Licencia Creative Commons Atribución-NoComercial-CompartirIgual 3.0 Costa Rica. Para más información envíe un mensaje a 


\section{Cuadro 2}

Vínculos organizativos entre las luchas

contra el Combo del ICE y el TLC

(2000 y 2006-2007)

\begin{tabular}{|l|l|}
\hline Vínculo & \multicolumn{1}{|c|}{ Descripción } \\
\hline $\begin{array}{l}\text { Experiencias compartidas en la } \\
\text { organización. }\end{array}$ & $\begin{array}{l}\text { Transformación de comités cívicos en } \\
\text { comités patrióticos. }\end{array}$ \\
\hline $\begin{array}{l}\text { Preocupación ciudadana por el } \\
\text { debilitamiento institucional y la pérdida de } \\
\text { la soberanía. }\end{array}$ & $\begin{array}{l}\text { La ciudadanía duda acerca de la } \\
\text { redistribución de los réditos obtenidos por } \\
\text { las empresas privadas que acechan para } \\
\text { apropiarse del patrimonio público. }\end{array}$ \\
\hline $\begin{array}{l}\text { Oposición entre la ciudadanía y la clase } \\
\text { política. }\end{array}$ & $\begin{array}{l}\text { Se visualiza a los políticos como sujetos } \\
\text { interesados en enriquecerse, } \\
\text { aprovechándose de su cercanía con el } \\
\text { Estado. }\end{array}$ \\
\hline
\end{tabular}

Fuente: Elaboración propia basada en Raventós, Ciska. (2018). Mi corazón dice no: el movimiento de oposición al TLC en Costa Rica. San José: EUCR. pp. 161-162.

En tercer lugar, con la aprobación del TLC, se abrió el candado que mantenía reservados ciertos monopolios al Estado como los seguros y las telecomunicaciones. Por la vía rápida, a partir de octubre de 2007, se empezó a dar trámite a proyectos legislativos, una agenda paralela conocida como Leyes de implementación; con la introducción de modificaciones sustanciales en materia de producción y de derechos de autor, entre otras.

Con la aprobación del TLC, se abrió el mercado de las telecomunicaciones a empresas privadas deseosas de incursionar en el país y ofrecer sus productos promocionales. En tan solo cinco años después de la aprobación del tratado, el ICE ha empezado a perder su condición de único operador en materia de telefonía móvil. En otros campos también son más que evidentes los efectos de este proceso de liberalización: en la entrada sin impuestos de cebollas traídas de Canadá; de carne de cerdo proveniente de Chile; y de cervezas a bajo costo, importadas de todos los lugares del mundo.

\section{(c) (1) (2)}

La Revista Estudios es editada por la Universidad de Costa Rica y se distribuye bajo una Licencia Creative Commons Atribución-NoComercial-CompartirIgual 3.0 Costa Rica. Para más información envíe un mensaje a 
Finalmente, se pueden acotar tres elementos que al fin y al cabo conforman un diagnóstico de situación actual de los movimientos sociales organizados. El primero hace alusión a que la mayor parte del sindicalismo tiene su base en el sector público; en tanto que en la empresa privada se ha distinguido por reprimir, incluso con la policía, cualquier intento de reivindicación obrera (Cabezas, 2015, p. 304). En segundo lugar, en palabras de Manuel Rojas (2007), se asiste a un proceso sociopolítico progresivo de mayor envergadura, reflejado en un "serio desajuste entre los mecanismos formales de representación y las necesidades reales de la ciudadanía..." (p. 177). En tercer término, en 2013 en el contexto de la celebración del centenario del primero de mayo, se hace notorio un interés proveniente de los sectores comerciales de despojar esta efeméride de su sentido social, sustituyéndola por el fomento del ocio y de elevar el nivel de las compras (Torres y Marín, 2015, pp. 266-267). Así por el estilo, la burguesía, en conjunto con los sectores gobernantes, preocupados estos últimos en promocionar el solidarismo, se han encargado de sepultar la tradición de lucha obrera que hizo posible la conquista de mejoras para las mayorías.

\section{Reflexiones finales}

Empobrecimiento, desigualdad creciente y un nuevo auge de los movimientos sociales, han marcado el destino de Costa Rica en los últimos cuarenta años. El contexto de la crisis de la década de 1980 constituye el punto de arranque de un período distinguido por un giro en el modelo de desarrollo del país, en momentos cuando las prácticas asociadas al interés de sustituir las importaciones presentaba hondas contradicciones, en medio de una asfixiante deuda que sumía a la economía en su conjunto. Poco a poco, se empezó a perfilar una nueva manera de insertar al país en la economía mundial, bajo directrices de organismos internaciones portadoras de recortes presupuestarios a programas sociales; la terapia del shock económico es solo una de sus versiones

\section{(c) (i) (2) (2)}

La Revista Estudios es editada por la Universidad de Costa Rica y se distribuye bajo una Licencia Creative Commons Atribución-NoComercial-CompartirIgual 3.0 Costa Rica. Para más información envíe un mensaje a 
más radicales; que a su vez, se convirtió en el motivo de marchas universitarias opositoras a la reducción del financiamiento de la educación pública.

La política continuada de reducción de la inversión social afectó inexorablemente el poder adquisitivo de los sueldos; de ahí la estocada recibida por los servidores públicos a quienes se les advirtió con actos contundentes, el final de la época de los salarios crecientes practicada durante los años de oro del Estado de Bienestar. Simultáneamente, la nueva lógica económica de acumulación empezó a generar jugosos réditos a un nuevo sector emergente, muy bien vinculado al gran capital y a actividades de empresas transnacionales; alentado por las políticas comerciales imperantes, muchas veces exentas del pago de impuestos. Este estrato residente en suntuosas casas amuralladas y apartadas del resto de las comunidades; constituyó el rostro más visible del éxito de una parte de la sociedad.

Frente a este panorama, los sectores medios, servidores públicos, campesinos, operarios de fábricas y todos aquellos sectores que no forman parte del pequeño grupo exitoso, se han sentido amenazados por las políticas estimuladas por los paladines de la austeridad estatal y de las ondas privatizadoras. De ahí se explica el estallido de la huelga magisterial en 1995; sus dirigentes levantaron la voz frente a un proyecto que modificaba el régimen de sus pensiones; en 2000, el afán de un gobierno dispuesto a aprobar una ley que transformaría el ICE, detonó en una sucesión de protestas callejeras a nivel regional y local que gritaban: “ICE sí, Combo no". Más tarde, en 2006-2007, marchas multitudinarias como expresión inmediata del descontento ciudadano, a manera de resistencia global, abarrotaron las calles de San José, en una lucha portadora de una defensa a la soberanía. Mientras tanto, la sociedad costarricense continúa transitando por las sendas de una desigualdad que no cesa en profundizarse.

\section{(c) (i) (-)}

La Revista Estudios es editada por la Universidad de Costa Rica y se distribuye bajo una Licencia Creative Commons Atribución-NoComercial-CompartirIgual 3.0 Costa Rica. Para más información envíe un mensaje a 


\section{Bibliografía}

Acuña, Víctor Hugo. (1984). Los orígenes de la clase obrera: las huelgas de 1920 por la jornada de ocho horas. San José: CENAP-CEPAS.

Aguilar, Marielos y Ramírez, Victoria. (1989). "Crisis económica y acción sindical en Costa Rica (1980-1987)". Revista de Ciencias Sociales. (44). pp. 64-65.

Alvarenga, Patricia. (2005). De vecinos a ciudadanos, movimientos comunales y luchas cívicas en la historia contemporánea de Costa Rica. San José: EUCR.

Araya, Jorge. (17 de mayo de 2017). "Pruebas de bachillerato siguen en debate". Semanario Universidad. Recuperado de http://semanariouniversidad.ucr.cr/pais/pruebas-bachillerato-siguen-debate/ Arias, Rafael, Sánchez, Leonardo y Giménez, Gregorio. (2016). Impacto sobre la educación sobre la pobreza en las regiones de planificación y cantones de Costa Rica. En Rafael Arias y Leonardo Sánchez (comp.). Educación, pobreza y desigualdad en Costa Rica. (pp. 3-62). San José: IICE-EUCR.

Barrantes, Alberto. (26 de octubre de 2013) "Empleo cierra puertas al $54 \%$ de las personas con discapacidad". La Nación. Recuperado de http://www.nacion.com/nacional/Empleo-cierra-puertas-personas-

Barrientos Valverde, Jorge. (2015). La ideología anticomunista en Costa Rica: guerra fría, discursos hegemónicos e identidades políticas, 1948-1962. Universidad de Costa Rica, Tesis de posgrado para optar por el título de maestría en Historia.

Boeglín, Nicolás. (28 de marzo de 2017). "Índice de desarrollo humano (2016) Costa Rica en el puesto 66". Diario Extra. Página Abierta. p. 1.

Bosque, Diego. (11 de febrero de 2018). "Ayuda que da Iglesia evangélica pesó en votos de los limonenses". La Nación. pp. 4-5 A.

Cabezas, Carlos. (2015). El sindicalismo en 100 años de lucha. Del liberalismo al neoliberalismo: los retos modernos. En Mario Torres, y Juan José Marín (comp.), Musa obrera, balances y desafíos de la clase trabajadora en el centenario del 1 de mayo en Costa Rica, 1973-2013. (pp. 302-314). San José: CIHAC.

\section{(c) (i) (2)(2)}

La Revista Estudios es editada por la Universidad de Costa Rica y se distribuye bajo una Licencia Creative Commons Atribución-NoComercial-CompartirIgual 3.0 Costa Rica. Para más información envíe un mensaje a revistaestudios.eeg@ucr.ac.cr. 
Castro, Carlos. (1995). Estado y sectores medios en Costa Rica: redimensionamiento de un pacto social. Cuadernos de Ciencias Sociales 36. San José: FLACSO.

Chinchilla, Sofía. (23 de abril de 2016). "150.000 jóvenes ni estudian ni trabajan en Costa Rica" La Nación. Recuperado de http://www.nacion.com/nacional/educacion/Numero-jovenes-nini-paisbaja_0_1556444369.html

Código Penal. http://www.oas.org/dil/esp/codigo_penal_costa_rica.pdf D'alolio, Ileana. (2007). "“Malos buses y peores tarifas”. La Asociación de Desarrollo de Hatillo contra Metrocoop y el Estado, 1989. Anatomía y acción de un movimiento social en el Área Metropolitana de San José a fines del siglo XX". Inter.c.a.mbio. (5), pp. 185-204. Recuperado de http: //revistas.ucr.ac.cr/index.php/intercambio/article/view/3906/3777

Espinoza, Marietta. (27 de julio de 2007). "La poesía que enojó al presidente" Diario Extra. p. 6.

García, George (2014). Formación de la clase media en Costa Rica. Economía, sociabilidad y discursos (1890-1950). San José: Arlekín.

Grosser, Kattya. (2012). La institución educativa en la actualidad: una tensión entre la independencia y el sometimiento. Universidad de Costa Rica, Tesis de posgrado para optar por el título de doctorado académico en estudios de la Sociedad y la Cultura.

Hidalgo-Capitán, A. (2003). Costa Rica en evolución: política económica y cambio estructural del sistema socioeconómico costarricense (1980-2002). San José, Costa Rica: Universidad de Huelva Publicaciones-EUCR.

Leitón, Patricia. (16 de octubre de 2015). "El 45\% de los desempleados son jóvenes entre 15 y 24 años", La Nación. Recuperado de http://www.nacion.com/economia/indicadores/desempleo-jovenes-

INEC_0_1518448222.html

\section{(C) $(\Theta \odot \odot$}

La Revista Estudios es editada por la Universidad de Costa Rica y se distribuye bajo una Licencia Creative Commons Atribución-NoComercial-CompartirIgual 3.0 Costa Rica. Para más información envíe un mensaje a revistaestudios.eeg@ucr.ac.cr. 
Leitón, Patricia y Ramírez, Esteban. (22 de octubre de 2015). "Pobreza en Costa Rica afecta al $21,7 \%$ de los hogares." La Nación. Recuperado de http://www.nacion.com/economia/politica-economica/Pobreza-Costa-Rica-afectahogares_0_1519648089.html

Menjívar, Mauricio. (2008). Luchas sociales en Costa Rica: de la crisis a la resistencia global (1979-2009). En Adalberto Santana. (coord.). Costa Rica en los inicios del siglo XXI. (pp. 83-107). México, CIALC-UNAM.

Molina, Silvia Elena y González, Eduardo. (2015). Historia de Costa Rica. San José, EUNED,

Mora, Minor y Pérez Juan Pablo. (2009). Se acabó la Pura Vida, San José: FLACSO.

Mora, Sindy. (2016). La política de la calle: organización y autonomía en la Costa Rica contemporánea. San José: EUCR.

Morales Rojas, Carla. (2011). Desigualdad y pobreza en Costa Rica: su expresión en las regiones. En Carla Morales. Desigualdad y pobreza en Costa Rica. (pp.148-160). San José: CEDAL.

Oviedo, Steven. (6 de agosto de 2015). "Solo 16\% de colegios logran promoción total en bachillerato". La Nación. Recuperado de http://www.nacion.com/nacional/educacion/Solo-colegios-logran-promocionbachillerato 0 1504249577.html

París, Luis. (2 de marzo de 2018). "Protagonismo electoral de la provincias costeras". La Nación. p. 20 A.

Pérez, Héctor. (2000). Breve historia contemporánea de Costa Rica. México, México: Fondo de Cultura Económica.

Pérez, Juan Pablo. (2012). Capítulo I Exclusión social. Una propuesta crítica para abordar las carencias materiales en América Latina. En Juan Pablo Pérez. Sociedades fracturadas. La exclusión social en Centroamérica. (pp. 15-32). San José, FLACSO.

\section{(๑) $\odot \odot$}

La Revista Estudios es editada por la Universidad de Costa Rica y se distribuye bajo una Licencia Creative Commons Atribución-NoComercial-CompartirIgual 3.0 Costa Rica. Para más información envíe un mensaje a revistaestudios.eeg@ucr.ac.cr. 
Pérez, Marian. (2006). Los impactos perversos de la segregación socioespacial en la ciudad de San José. En Anne-Marie Séguin, (edit.). La segregación socioespacial urbana: Una mirada sobre Puebla, Puerto España, San José y San Salvador. (pp. 174-175). San José: FLACSO.

Programa Estado de la Nación en Desarrollo Humano Sostenible. (2013). Decimonoveno Informe Estado de la Nación. San José: PEN.

Programa de Estado de la Nación en Desarrollo Humano Sostenible. (2015a) Quinto Estado de la Educación Costarricense. San José: E Digital ED.

Programa Estado de la Nación en Desarrollo Humano Sostenible. (2015b). Vigésimo primer Informe Estado de la Nación. San José: PEN.

Proyecto Estado de la Nación. (1995). Estado de la nación en desarrollo sostenible. San José: PEN.

Proyecto Estado de la Nación. (2016). Quinto Informe Estado de la Región en Desarrollo Humano Sostenible. San José: PEN

Raventós, Ciska. (2018). Mi corazón dice no: el movimiento de oposición al TLC en Costa Rica. San José: EUCR.

Rovira, Jorge. (1989). Costa Rica en los años 80. San José, Costa Rica: Porvenir. Rivera, Ernesto. (12 de noviembre de 2014). "Hogares con jefatura femenina se duplicaron en 25 años". Semanario Universidad. Recuperado de http://semanariouniversidad.ucr.cr/pais/hogares-con-jefatura-femenina-seduplicaron-en-25-aos/

Robles, Arodys. Capítulo 2 ¿Quiénes son y dónde están las personas adultas mayores? I Informe del estado de la situación de la persona adulta mayor en Costa Rica, 2008, pp. 12 y subsiguientes. ccp.ucr.ac.cr/espam/descargas/ESPAM_cap2web.pd

Rodríguez, Andrea. (7 de agosto de 2016). "Las dos caras de la población trabajadora del país". El Financiero. pp. 4-5.

\section{(c) (i) (2)}

La Revista Estudios es editada por la Universidad de Costa Rica y se distribuye bajo una Licencia Creative Commons Atribución-NoComercial-CompartirIgual 3.0 Costa Rica. Para más información envíe un mensaje a revistaestudios.eeg@ucr.ac.cr. 
Rojas, Manuel. (2007). La representación política ¿En crisis o en transición? En Jorge Rovira. (edit.). Desafíos de la Costa Rica actual. (pp. 177-192). San José: EUCR.

Román, Isabel. (21 de febrero de 2018). "Una llamada de atención para el MEP". La Nación. p. 22 A.

Séguin, Anne-Marie. Introducción. En Séguin, Anne-Marie (editora), La segregación socio-espacial urbana: Una mirada sobre Puebla, Puerto España, San José y San Salvador, San José, FLACSO, 2006, pp. 10-29.

Sojo, Carlos. (1997). Los de en medio. San José: FLACSO.

Sojo, Carlos. (2010). Igualiticos: la construcción social de la desigualdad en Costa Rica. San José, FLACSO-PNUD,

Torres, Mario y Marín, Juan José. (2015). Primero de Mayo 2013. Una centenario en disputa. Una perspectiva histórica. En Mario Torres, y Juan José Marín. (comp.). Musa obrera, balances y desafíos de la clase trabajadora en el centenario del 1 de mayo en Costa Rica, 1973-2013. (pp. 266-267). San José: CIHAC.

Trejos, María Eugenia y Valverde José Manuel. (1993). "Diez años de luchas urbanas en Costa Rica 1982-1992". Revista de Ciencias Sociales, (61) pp. 7-25. Vega, Mylena. (1996). "Cambios en la sociedad costarricense en las décadas de los ochenta y noventa". Anuario de Estudios Centroamericanos. (22). pp. 129-146. 